ORIGINAL ARTICLE

\title{
Onset of puberty, menstrual frequency, and body fat in elite rhythmic gymnasts compared with normal controls
}

\section{P Klentrou, M Plyley}

See end of article for authors' affiliations Correspondence to: Dr Klentrou, Faculty of Applied Health Sciences, Brock University, StCatharines, Ontario, Canada L2S $3 \mathrm{~A} 1$; nota.klentrou@brocku.ca

Accepted

17 December 2002
Objectives: To assess the prevalence of delayed menarche and abnormal menstrual patterns, as well as the association of menstrual status with physical training in elite rhythmic gymnasts from Greece and Canada.

Methods: Fifteen Greek (mean (SEM) age 14.5 (0.2) years) and 30 Canadian (mean (SEM) age 14.7 (0.4) years) rhythmic gymnasts were surveyed for age at menarche, menstrual frequency, and training profile, and measured for height, weight, and percentage body fat (\%BF). Seventy eight healthy adolescents served as country specific non-active controls: 38 Greek non-athletes (mean (SEM) age 14.5 (0.1) years) and 40 Canadian non-athletes (mean (SEM) 14.2 (0.1) years).

Results: Of the Greek gymnasts, 79\% had not yet menstruated compared with $34 \%$ of the Canadian gymnasts. Menarche was significantly $(p<0.01)$ delayed in the rhythmic gymnasts (composite mean 13.8 (0.3) years, $n=45$ ) compared with the controls (composite mean $12.5(0.1)$ years, $n=78)$. There was no significant difference between Greek and Canadian gymnasts for the age at menarche (14.2 (0.3) $v$ 13.6 (1.2) years respectively). Menstrual irregularities were reported in $78 \%$ (61\% oligomenorrhoeic and $17 \%$ amenorrhoeic) of the menarcheal athletes. Menarcheal gymnasts were found to be significantly $(p<0.05)$ taller and heavier, with a higher \% BF and a lower training frequency and training duration $(p<0.05)$ than the premenarcheal gymnasts. Overall, the mean \%BF of the gymnasts was significantly lower $(p<0.05)$ than that of the control subjects. The Canadian controls exhibited a significantly $(p<0.05)$ greater \%BF than the Greek controls of the same age.

Conclusion: Delayed menarche, menstrual irregularities, and low body fat are common in elite rhythmic gymnasts. Premenarcheal gymnasts train more often and for longer, and have a lower body mass index and less body fat, than menarcheal gymnasts. Prospective studies are needed to explore further these and other factors associated with delayed menarche and menstrual irregularities in female athletes.
A s more girls are becoming involved in intense athletic training at a young age, health issues centring on the female athlete triad have become a concern. Disordered eating, menstrual dysfunction, and osteoporosis are the three interrelated components of the female athlete triad, a potentially serious syndrome often seen in physically active girls and women, which can result in decreased performance, both short and long term morbidity, and even mortality. ${ }^{1}$

Disordered eating refers to eating behaviours used to lose weight or achieve a lean appearance. ${ }^{1}$ These behaviours can cause disturbances in menstrual function, which may be seen as primary amenorrhoea (defined as the absence of menstruation by age 16), secondary amenorrhoea (defined as the absence of menses for three or more months in women who have reached menarche), or oligomenorrhoea (defined as menstrual cycle duration greater than 36 days). A high incidence of secondary amenorrhoea has been reported for athletes in certain sports. ${ }^{2}$ Among adolescent athletes, the prevalence of "athletic amenorrhoea" is reported to be as high as $44 \% .^{3}$

Abnormal menstrual patterns have been shown to have a negative effect on bone mineralisation and thus may have serious short and long term consequences, including an increased incidence of stress fractures and osteoporosis. ${ }^{1} 45$ Undernutrition is also associated with delays in growth and sexual maturation and even infertility. ${ }^{467}$

In some activities, especially aesthetic sports and those in which high power to body mass is important, an increase in body weight can negatively influence performance. ${ }^{8}$ As a result, the life of an adolescent athlete often involves a combination of intense physical training combined with pressure to meet unrealistic weight goals as a means of improving performance and/or visual appeal. Consequently, the adolescent athlete is often prone to disordered eating patterns. ${ }^{9}$ The combination of intensive exercise and undernutrition may have a profound effect on the release of gonadotropins, activation of the gonadal axis, the timing of puberty, and the onset of menstrual disorders in adolescent athletes. ${ }^{6}{ }^{10}{ }^{11}$ In addition, less severe forms of food restriction have been associated with inadequate luteal phases, anovulation, and abnormal surges of luteinising hormone and follicle stimulating hormone during the menstrual cycle. ${ }^{7}$

Female athletes who begin training at a young age often have a delay in menarche. ${ }^{12}$ The time at which athletic training was initiated has been implicated as a factor in delayed menarche because intense training before puberty may alter hypothalamic-pituitary function. Body composition has also been used to explain the delayed menstruation and menstrual cycle irregularities among elite athletes. Although not supported by current opinion, Frisch and McArthur ${ }^{13}$ have theorised an association between menstrual regularity and the level of body fat, suggesting that a level of at least $17 \%$ body fat is critical for the onset of menstruation and the maintenance of a normal cycle. On the other hand, more recent studies have suggested that delayed menarche may be due to genetic factors, and that girls who mature later often self select sports that require high relative strength and small bodies, such as gymnastics. ${ }^{14}{ }^{15}$ According to Kaprio et al, ${ }^{16}$

Abbreviations: \%BF, percentage of body fat; $\mathrm{BMI}$, body mass index 
$37 \%$ of the variance in the age at menarche was found to be attributed to additive genetic factors. In addition, the correlation between the additive genetic effects on age at menarche and body mass index (BMI) was 0.57 , indicating that a substantial proportion of genetic effects are common. ${ }^{16}$

In rhythmic gymnastics, intense training usually starts long before menarche, and success is strongly influenced by visual appeal and body aesthetics. Rhythmic gymnasts are often required to meet unrealistic weight goals to attain or maintain a favourable physique. Hence, they are at risk of developing poor eating habits ranging from poor nutrition and/or insufficient energy intake to serious eating disorders. Few or no data exist on either menstrual disorders or eating habits of girls involved in rhythmic sports gymnasts programmes. In artistic gymnasts, who also often start high intensity training before puberty, there is considerable controversy as to whether growth potential is affected by training. Growth potential has been found to be reduced and menarche has been reported to be delayed in artistic gymnasts. ${ }^{17-19}$ However, this delay may not be attributed to gymnastics per se, but rather to genetic factors or energy intake that is inadequate to meet the demands of both growth and sport. ${ }^{20}{ }^{21}$ On the other hand, BMI was found to be decreased in a study of gymnasts aged 7-10 years, but the difference was suggested to be the result of selection of lean athletes. ${ }^{22}$ This is also supported by a study by Damsgaard et $a l^{23}$ in which longitudinal data indicated that the individual differences in body size among sports participants already exists at an early age ( $2-4$ years) suggesting genetic influences.

The aims of this study were: (a) to investigate the occurrence of delayed menarche and abnormal menstrual patterns among elite adolescent rhythmic sports gymnasts from Canada and Greece; $(b)$ to compare the two groups of athletes, both with each other and with a sample of age and country specific non-athletes; $(c)$ to examine the relation between physical training characteristics and menstrual status in elite rhythmic gymnasts.

\section{METHODS}

Fifteen elite Greek rhythmic gymnasts from the National Training Center in Athens and 30 elite rhythmic gymnasts from clubs across Canada, including athletes from two National High Performance Centers (Ontario and Manitoba), were invited to participate in the study. Age at menarche, the pattern of their menses, details of training history, and volume of training were recorded. The gymnasts were also asked to complete a non-validated questionnaire of medical history, which included questions about use of oral contraceptives and prior diagnosis of an eating disorder.

Before the start of data collection, informed consent was obtained from each participant or her parents according to the research plan approved by the research ethics review committee. Seventy eight healthy adolescents from Greece and Canada (none were members of a competitive sports team) were also surveyed for age at menarche and frequency of menses.

The frequency and duration of training for the gymnasts was determined from a combination of: $(a)$ the coaches' training schedule; $(b)$ the sport participation questionnaire (SPQ), a validated questionnaire used to estimate the amount of participation in physical activity and the nature of the participation in children; $(c)$ the habitual activity estimation scale (HAES), a validated questionnaire that assesses all forms of habitual activity in terms of the number of hours of activity a day. ${ }^{24}{ }^{25}$ The HAES has been used previously to measure the duration and intensity of daily activity of children from infancy through adolescence. ${ }^{24} 25$ Both the
SPQ and HAES have a demonstrated test-retest reliability in excess of 0.80 when reported for two days. ${ }^{24} 26$

The following anthropometric measurements were made on all subjects: total body height (in $\mathrm{cm}$ ) and body mass (in $\mathrm{kg}$ ) were measured using standard techniques, and BMI was calculated. Skinfold thickness (in mm) was assessed at two sites (triceps and subscapular) using a Harpenden calliper, and the percentage of body fat (\%BF) was calculated using the prediction equations developed for children $\leqslant 18$ years of age by Slaughter et al. ${ }^{27}$

Descriptive statistics were used to describe the menstrual profile. One way analyses of variance were used to test differences among groups. The relation (Pearson productmoment correlation) between physical/training characteristics and the frequency of menses was examined using linear regression analysis.

\section{RESULTS}

Table 1 gives the mean age, height, weight, BMI, and \%BF for both the rhythmic gymnasts and the age matched control, for each country. The mean (SEM) age of the gymnasts was 14.5 $(0.2)$ and $14.7(0.4)$ years for the Greek and Canadian groups respectively. The mean body weight, BMI, and \%BF of the gymnasts from each country were significantly lower $(p<0.05)$ than of the country specific controls of the same age (table 1). The Canadian controls had a significantly higher BMI and \%BF than the Greek control group (table 1). None of the subjects reported use of oral contraceptives or having been medically diagnosed with eating disorders.

Among the Greek rhythmic gymnasts, $79 \%$ had not yet begun to menstruate compared with $34 \%(p<0.05)$ of the Canadian athletes (fig 1). The mean age at menarche for all rhythmic gymnasts was 13.8 (1.3) years. This represents a significant $(\mathrm{p}<0.05)$ delay compared with the controls $(12.5$ (0.1) years), with no significant difference between countries.

All girls from both control groups had achieved regular menstruation at the time of the study and none reported any menstrual irregularities, whereas a considerable percentage $(78 \%)$ of the menarcheal athletes reported menstrual irregularities. A significantly $(p<0.01)$ higher incidence of oligomenorrhoea and amenorrhoea was found in the rhythmic gymnasts than the controls. Oligomenorrhoea was reported in $61 \%$ and secondary amenorrhoea was reported in $17 \%$ of these gymnasts. Figure 1 shows the menstrual status for the rhythmic gymnasts of each country.

One way analyses of variance revealed significant differences between menarcheal and premenarcheal rhythmic gymnasts in terms of height $(p<0.01)$, weight $(p<0.01)$, BMI $(p<0.01)$, and \%BF $(p<0.01)$, as well as training frequency and duration $(\mathrm{p}<0.05)$, yet both groups had been training for a similar period (table 2). All of the gymnasts had been competing for 3-9 consecutive years, with training ranging from 15 to 36 hours a week.

No significant differences were found in \%BF, height, weight, BMI, training experience, training frequency, or duration between the eumenorrhoeic and oligomenorrhoeic athletes (table 3).

\section{DISCUSSION \\ Age of menarche}

The age of menarche for those rhythmic gymnasts who had achieved menarche was delayed compared with both the controls in this study $(\mathrm{p}<0.05)$ and the controls in other studies (table 4). ${ }^{17} 28$ However, $79 \%$ of the Greek and $34 \%$ of the Canadian gymnasts had not yet started to menstruate; the mean age of these groups was 14.5 and 14.7 years respectively. Although there are no available data on the menstrual patterns in rhythmic gymnasts, an examination of 
Table 1 Chronological age, physical characteristics, and body fat of rhythmic gymnasts and non-athletes

\begin{tabular}{|c|c|c|c|c|}
\hline & \multicolumn{2}{|c|}{ Rhythmic gymnasts } & \multicolumn{2}{|l|}{ Non-athletes } \\
\hline & Greek $(n=15)$ & Canadian $(n=30)$ & Greek $(n=38)$ & Canadian $(n=40)$ \\
\hline $\begin{array}{l}\text { Age (years) } \\
\text { Height }(\mathrm{cm}) \\
\text { Weight }(\mathrm{kg}) \\
\mathrm{BMI}(\mathrm{kg} / \mathrm{m}) \\
\% \mathrm{BF}\end{array}$ & $\begin{array}{l}14.5(0.2) \\
160.0(1.2) \\
43.4(1.3)^{*} \\
16.9(0.3)^{*} \\
14.3(0.5)^{*}\end{array}$ & $\begin{array}{l}14.7(0.4) \\
163.4(1.8) \\
45.9(1.7)^{\star} \\
17.2(0.3)^{\star *} \\
16.2(0.4)^{*}\end{array}$ & $\begin{array}{l}14.5(0.1) \\
166.2(1.5) \\
52.2(1.8)^{*} \\
18.9(0.6)^{*} \dagger \\
21.1(1.0)^{*} \dagger\end{array}$ & $\begin{array}{l}14.2(0.1) \\
161.8(1.4) \\
58.4(2.1)^{*} \\
22.3(0.7)^{* *} \dagger \\
25.1(1.3)^{*} \dagger\end{array}$ \\
\hline
\end{tabular}

Values are means (SEM).

${ }^{*} p<0.05,{ }^{* *} p<0.01$ between groups; $\uparrow p<0.05$ between countries.

$\mathrm{BMI}$, Body mass index; \%BF, percentage body fat.

the literature (table 4) reveals that the age at menarche of the Greek rhythmic gymnasts is similar to that reported for female artistic gymnasts and ballet dancers, which has been reported to be significantly $(\mathrm{p}<0.05)$ delayed compared with controls. ${ }^{17} 3031$ The age at menarche of the Canadian rhythmic gymnasts is similar to that also reported as delayed for other athletes including more recent data for ballet dancers. ${ }^{28} 293233$ The most delayed age at menarche in our study was recorded among the oligomenorrhoeic (13.8 (1.2) years) and amenorrhoeic (14.4 (1.0) years) rhythmic gymnasts.

It is interesting that the menarcheal gymnasts had a significantly lower training frequency and training duration than the premenarcheal gymnasts (table 2). Theintz et $a l^{18}$ have suggested that gymnasts advance through puberty without a normal pubertal growth spurt. They hypothesised that when puberty is temporarily interrupted by exercise, skeletal age maturation often stalls as growth slows and sex steroids fall to low levels. However, growth potential may not be affected below a certain threshold of training intensity, which may explain the difference in training duration and training frequency between the menarcheal and premenarcheal gymnasts. ${ }^{19}$ As reported elsewhere, girls who mature later often self select sports that require a high relative strength and small bodies, such as gymnastics. ${ }^{14}{ }^{15}$ The late maturing, premenarcheal body type favours athletic success in this type of activity. This observation is in accordance with the present data in that the premenarcheal gymnasts were not only

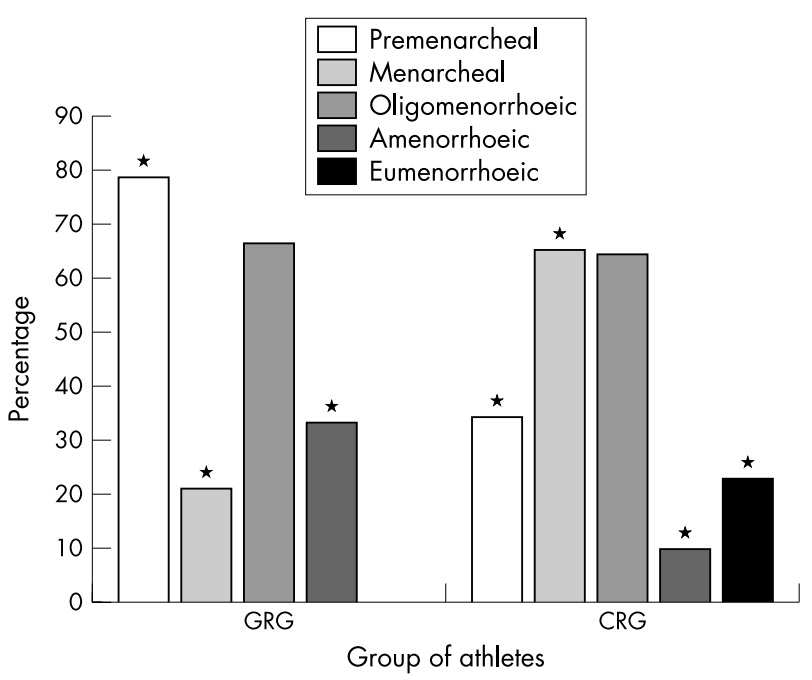

Figure 1 Distribution (\%) of menstrual status and menarcheal status reported by rhythmic gymnasts from Greece (GRG) and Canada (CRG). ${ }^{*}$ Significant difference $(p<0.05)$ within groups. There were no eumenorrhoeic Greek gymnasts so this bar does not appear. significantly thinner, but were also significantly shorter, than the menarcheal gymnasts (table 2).

Previous studies have also suggested that the age of the onset of pubertal development varies greatly, and is influenced by nutrition, heredity, state of health, percentage of body fat, and other factors. ${ }^{19}{ }^{34}$ The rhythmic gymnasts who had not yet reached menarche exhibited a significantly lower BMI and less body fat than both the menarcheal gymnasts and the non-athletes of the same age, both of which achieved regular menstruation. As reported, while engaging in intensive training, many young elite athletes, including gymnasts, have an unsatisfactory nutritional status and very low body fat. ${ }^{12} 183031$

\section{Menstrual frequency}

Frisch et al ${ }^{12}$ have reported that college age girls who began training before menarche were more prone to delayed menarche and secondary amenorrhoea than those who began training after menarche. ${ }^{12}$ All gymnasts in our study reported training for an average of 23-24 hours a week, and most of them began training at an early age (7-8 years) - that is, several years before puberty. It was therefore not surprising that only $21 \%$ of the gymnasts in this study reported regular menstrual cycles.

Two of the three Greek menarcheal gymnasts reported secondary amenorrhoea; their mean age of menarche was 13.9 (0.7) years, and at the time of the study their mean chronological age was $14.2(0.3)$ years. As irregular menses immediately after the onset of menarche is not uncommon, this result may complicate the findings from those gymnasts that were only one year postmenarcheal. ${ }^{34}{ }^{35}$ On the other hand, $65 \%$ of Canadian gymnasts indicated oligomenorrhoea; these gymnasts had a mean age of menarche of 13.6 (1.2) years, and at the time of the study, their mean age was 16.4 (1.3) years. In this case, the findings have more significance in terms of interpreting oligomenorrhoea.

Table 2 Physical and training characteristics of menarcheal (M-RG) and premenarcheal (PM-RG) gymnasts

\begin{tabular}{lll}
\hline Variable & PM-RG $(\mathbf{n}=22)$ & M-RG $(\mathbf{n = 2 3 )}$ \\
\hline Weight $(\mathrm{kg})$ & $39.5(2.5)^{\star *}$ & $49.7(1.7)$ \\
Height $(\mathrm{cm})$ & $156.1(2.2)^{* *}$ & $167.3(1.5)$ \\
$\mathrm{BMI}(\mathrm{kg} / \mathrm{m})$ & $16.3(0.3)^{\star *}$ & $18.0(0.3)$ \\
\%BF & $13.9(0.4)^{* *}$ & $17.5(0.4)$ \\
Training experience (years) & $6.8(1.8)^{*}$ & $6.7(3.4)$ \\
Training frequency (days/week) & $6.4(0.8)^{*}$ & $5.0(0.1)$ \\
Training duration (h/day) & $5.6(0.6)^{*}$ & $4.5(0.3)$ \\
\hline
\end{tabular}

Values are means (SEM).

${ }^{*} \mathrm{p}<0.05,{ }^{* *} \mathrm{p}<0.01$ compared with $\mathrm{M}-\mathrm{RG}$

$\mathrm{BMI}$, Body mass index; \%BF, percentage body fat. 
Table 3 Physical and training characteristics between eumenorrhoeic (E-RG), and combined amenorrhoeic and oligomenorrhoeic (AO-RG) rhythmic gymnasts

\begin{tabular}{lll}
\hline Variable & AO-RG $(\mathbf{n}=18)$ & E-RG $(\mathbf{n}=5)$ \\
\hline Weight $(\mathrm{kg})$ & $49.2(1.8)$ & $49.6(1.8)$ \\
Height $(\mathrm{cm})$ & $166.4(1.8)$ & $166.3(2.2)$ \\
$\mathrm{BMl}(\mathrm{kg} / \mathrm{m})$ & $17.7(0.4)$ & $18.2(0.5)$ \\
\%BF & $17.5(0.4)$ & $17.5(0.6)$ \\
Training experience (years) & $6.8(1.8)$ & $6.7(3.4)$ \\
Training frequency (days/week) & $6.4(0.9)$ & $6.0(0.0)$ \\
Training duration (h/day) & $3.6(0.6)$ & $3.7(0.3)$ \\
\hline
\end{tabular}

Values are means (SEM). No significant differences were found between variables.

These findings are in accordance with those of Lindboe and Slettebo, ${ }^{36}$ who examined eight elite rhythmic gymnasts in Norway, with $50 \%$ of them reporting secondary amenorrhoea. Available data from artistic gymnastics have also shown amenorrhoea in $33 \%$ of female gymnasts, and irregular cycles in $53 \%$ of them. ${ }^{30}$

\section{Body composition}

In reference to body composition, females who are physically active and are excessively lean, increase their chances of oligomenorrhoea or amenorrhoea. ${ }^{77-39}$ The rhythmic gymnasts in our study had significantly lower body weight, BMI, and \%BF than the normal control subjects (table 1 ). The BMI values in our study conform to that of young female gymnasts reported by Damsgaard et al ${ }^{23}(17.3$ (0.53)), which was significantly lower than reported for other young athletes, such as swimmers and handball players. This is in contrast with the study of Lindboe and Slettebo ${ }^{36}$ in which the rhythmic gymnasts had a similar mean body weight and BMI to that of the controls. As in our study, the gymnasts in the study by Lindboe and Slettebo were not closely surveyed for eating disorders. In our study the absence of medical diagnosis was considered as an indication of a low incidence of eating disorders. However, the study is limited in detecting eating disorders because the medical history was self reported and the questionnaire was not

Table 4 Age of menarche in rhythmic gymnasts, artistic gymnasts, ballet dancers, track and field athletes, and non-athletes

\begin{tabular}{|c|c|c|}
\hline Subjects & $\begin{array}{l}\text { Age at } \\
\text { menarche }\end{array}$ & Source \\
\hline \multicolumn{3}{|l|}{ Athletes } \\
\hline $\begin{array}{l}\text { Rhythmic gymnasts } \\
\text { (Canada, } \mathrm{n}=30 \text { ) }\end{array}$ & $13.6(1.2)^{*}$ & This study \\
\hline $\begin{array}{l}\text { Rhythmic gymnasts } \\
\text { (Greece, } n=15 \text { ) }\end{array}$ & $14.2(0.3)^{*}$ & This study \\
\hline Artistic gymnasts ( $n=22$ ) & $14.5(1.4)^{*}$ & Lindholm et $a l^{77}$ \\
\hline $\begin{array}{l}\text { Track and field athletes } \\
(\mathrm{n}=66)\end{array}$ & $13.6(0.2)^{*}$ & Malina et $a^{88}$ \\
\hline Swimmers $(n=69)$ & $13.8(0.2)^{*}$ & Constantini \& Warren ${ }^{29}$ \\
\hline Artistic gymnasts $(n=20)$ & 14.2 & Calabrese $^{30}$ \\
\hline Ballet dancers $(n=25)$ & 14.3 & Calabrese et $a^{\beta 1}$ \\
\hline Ballet dancers $(n=97)$ & $13.5^{*}$ & Pigeon et $a^{\beta 2}$ \\
\hline $\begin{array}{l}7 \text { Sports (mixture of athletes; } \\
\mathrm{n}=109 \text { ) }\end{array}$ & $13.8(1.5)$ & Malina ef $a^{\beta 3}$ \\
\hline \multicolumn{3}{|l|}{ Non-athletic girls } \\
\hline Canada $(n=40)$ & $12.3(0.8)$ & This study \\
\hline Greece $(n=38)$ & $12.8(0.9)$ & This study \\
\hline Sweden $(n=22)$ & $13.2(0.9)$ & Lindholm et $a l^{77}$ \\
\hline United States $(n=30)$ & $12.2(1.6)$ & Malina et $a^{p^{8}}$ \\
\hline Israel $(n=279)$ & $13.0(0.1)$ & Constantini \& Warren ${ }^{29}$ \\
\hline France $(n=30)$ & 12.0 & Pigeon et $\left.a\right|^{\beta 2}$ \\
\hline
\end{tabular}

\section{Take home message}

High performance rhythmic gymnasts have a lower body mass index and percentage body fat than non-training girls of the same age. The intense physical training of those involved in rhythmic gymnastics is associated with delayed development of the normal menstrual pattern, with menarche being delayed by as much as $1.5-2.0$ years.

validated. It is possible that undetected eating disorders was a confounding variable associated with the increase in menstrual dysfunction.

An unexpected finding of this study was the significant difference observed in both BMI and \%BF between the Canadian and Greek control groups. Canadian girls not involved in competitive sports seem to be heavier and have more body fat than Greek non-athletes of similar age. This is an important finding that may reveal a combined effect of habitual physical inactivity and environmental and/or nutritional factors and requires further investigation.

In conclusion, menarche was delayed in 32 of 45 elite rhythmic gymnasts, and menstrual irregularities were reported in $78 \%$ of the menarcheal athletes (61 oligomenorrhoeic and $17 \%$ amenorrhoeic). All gymnasts were found to weigh significantly less than controls. The premenarcheal gymnasts had lower BMI and less body fat than the menarcheal athletes, yet the oligomenorrhoeic and amenorrhoeic gymnasts did not differ in body size or composition from the eumenorrhoeics. The premenarcheal gymnasts trained more often and for longer than the menarcheal gymnasts. However, because of the cross sectional nature of this study, a cause-effect relation between intense training and the development of the reproductive cycle cannot be made, but further study is warranted.

Future research should include a detailed nutritional profile of these athletes. Recent research suggests that athletic amenorrhoea may be prevented or reversed by an improved energy balance. ${ }^{40}$ Although research in the area is still inconclusive, an energy deficit state is suggested to be the primary mechanism responsible for the hypothalamic reproductive dysfunction in athletes. Finally, an in depth hormonal analysis would help to further evaluate menstrual dysfunction among elite rhythmic gymnasts. Given the potential problems of hormonal dysfunction and energy deficit for reproductive health and bone, further research is warranted in young female athletes.

\section{Authors' affiliations}

P Klentrou, M Plyley, Faculty of Applied Health Sciences, Brock University, St-Catharines, Ontario, Canada

\section{REFERENCES}

1 Yeager KK, Agostini R, Nattiv A, et al. The female athlete triad. Med Sci Sports Exerc 1993;25:775-7.

2 Loucks AB, Horvath SM. Athletic amenorrhea: a review. Med Sci Sports Exerc $1985 ; 17: 56-72$.

3 Loucks $\mathbf{A B}$. Effects of exercise training on the menstrual cycle: existence and mechanisms. Med Sci Sports Exerc 1990;22:275-80.

4 Drinkwater BL, Nilson $\mathrm{K}$, Chesnut $\mathrm{CH}$, et al. Bone mineral content of amenorrhoeic and eumenorrhoeic athletes. N Engl J Med 1984;31 1:277-81.

5 Difiori JP. Menstrual dysfunction in athletes. How to identify and treat patients at risk for skeletal injury. Postgrad Med 1995;97:143-56.

6 Loucks AB, Mortola JF, Girton L, et al. Alterations in the hypothalamicpituitary-ovarian and the hypothalamic-pituitary-adrenal axes in athletic women. J Clin Endocrinol Metab 1989:68:402-11.

7 Loucks AB, Vaitukaitis J, Cameron JL, et al. The reproductive system and exercise in women. Med Sci Sports Exerc 1992;24(suppl):S288-93.

8 Wilmore JH. Body weight standards and athletic performance. In: Brownell KD, Rodin J, Wilmore JH, eds. Eating, body weight and performance 
in athletes: disorders of modern society. Philadelphia: Lea and Febiger, 1992:315-29.

9 Wilmore JH. Eating and weight disorders in the female athlete. Int I Sports Nutr 1991:1:104-17.

10 Warren MP. The effects of exercise on pubertal progression and reproductive function in girls. J Clin Endocrinol Metab 1980;51:1150-7.

11 Bonen A, Belcastro AN, Ling WY, et al. Profiles of selected hormones during menstrual cycles of teenage athletes. J Appl Physiol 1981;50:545-51.

12 Frisch R, Gotz-Welbergen AV, McArthur JW. Delayed menarche and amenorrhea of college athletes in relation to age of onset of training. JAMA 1981;246:1559-63.

13 Frisch RE, McArthur JW. Menstrual cycles: fatness as a determinant of minimun weight for height necessary for their maintenance or onset. Science 1974; 185:949-51.

14 Loucks AB. The reproductive system and physical activity in adolescents. In: Blimkie CJR, Bar-Or O, eds. New horizons in pediatric exercise science. 1995:27-37.

15 Baxter-Jones ADG, Helms PJ. Effects of training at a young age: a review of the training of young athletes (TOYA) study. Pediatrics and Exercise Science 1996:8:310-27.

16 Kaprio J, Rimpela A, Winter T, et al. Common genetic influences on BMl and age at menarche. Hum Biol 1995;67:739-53.

17 Theintz GE, Howald $H$, Weiss U, et al. Evidence for a reduction of growth potential in adolescent female gymnasts. J Pediatr 1993;122:306-13.

18 Theintz GE, Ladame F, Howald H, et al. L'enfant, la croissance et le sport de haut niveau. Schweiz Z Med Traumatol 1994;3:7-15.

19 Lindholm C, Hagenfeldt K, Rangertz B. Pubertal development in elite juvenile gymnasts: effects of physical training. Acta Obstet Gynaecol Scand 1994;73:269-73.

20 Ledoux M, Brisson G, Peronnet F. Nutritional habits of young female gymnasts. Med Sci Sports Exerc 1983;14:145.

21 Ersoy G. Dietary status and anthropometric assessment of child gymnasts. J Sports Med Phys Fitness 1991;31:577-80.

22 Benardot D, Czerwinski C. Selected body composition and growth measures of junior elite gymnasts. J Am Diet Assoc 1991;91:29-33.

23 Damsgaard R, Bencke J, Matthiesen G, et al. Is pubertal growth adversely affected by sport? Med Sci Sports Exerc 2000;32:1698-703.
24 Hay J. Adequacy and predilection for activity in children. Clin J Sport Med 1992;2:192-201.

25 Hay JA. Development and testing of the Habitual Activity Estimation Scale. In: Welsman J, Kirby B, eds. Children and exercise XX. Exeter: Washington Singer Press, 1995;2:125-9.

26 Hay JA, Atkinson S, Halton J. An examination of the reliability of the Habitual Activity Estimation Scale (HAES). Pediatric Work Physiology Symposium XVIII. Odense, Denmark, 1995:49.

27 Slaughter MH, Lohman TG, Boileau RA, et al. Skinfold equations for estimation of body fatness in children and youth. Hum Biol 1988;60:709-23.

28 Malina R. Menarche in athletes; a synthesis and hypothesis. Ann Hum Biol 1973;10:1-24.

29 Constantini NW, Warren MP. Menstrual dysfunction in swimmers: a distinct entity. J Clin Endocrinol Metab 1995;80:2740-4.

30 Calabrese LH. Nutritional and medical aspects of gymnastics. Clin Sports Med 1985;4:23-30

31 Calabrese LH, Kirkendall DT, Floyd M. Menstrual abnormalities, nutritional patterns, and body composition in female classical ballet dancers. Physician and Sports Medicine 1983;11:86-98.

32 Pigeon P, Oliver I, Charlet JP, et al. Intensive dance practice: repercussions on growth and puberty. Am J Sports Med 1997;25:243-7.

33 Malina RM, Ryan RC, Bonci CM. Age at menarche in athletes and their mothers and sisters. Ann Hum Biol 1994:21:417-22.

34 Hamm T. Physiology of normal female bleeding. NAACOG Clinical Issues 1991;2:289-94.

35 Vollman R. The menstrual cycle. Philadelphia: Saunders, 1977.

36 Lindboe CF, Slettebo M. Are young female gymnasts malnourished? An anthropometric, electrophysiological and histological study. Eur J Appl Physiol 1984;52:457-62

37 Brooks-Gunn J, Warren MP, Hamilton LH. The relationship of eating disorders to amenorrhea in ballet dancers. Med Sci Sports Exerc 1987;19:41-4.

38 Brownell KD, Steen SN, Wilmore JH. Weight regulation practices in athletes: analysis of metabolic and health effects. Med Sci Sports Exerc 1987; 19:546-56.

39 Mansfield M, Emans J. Growth in female gymnasts: should training decrease during puberty? J Pediatr 1993;122:237-40.

40 Loucks $A B$, Heath EM. Induction of low-T3 syndrome in exercising women occurs at a threshold of energy availability. Am J Physiol 1994;266:R817-23.

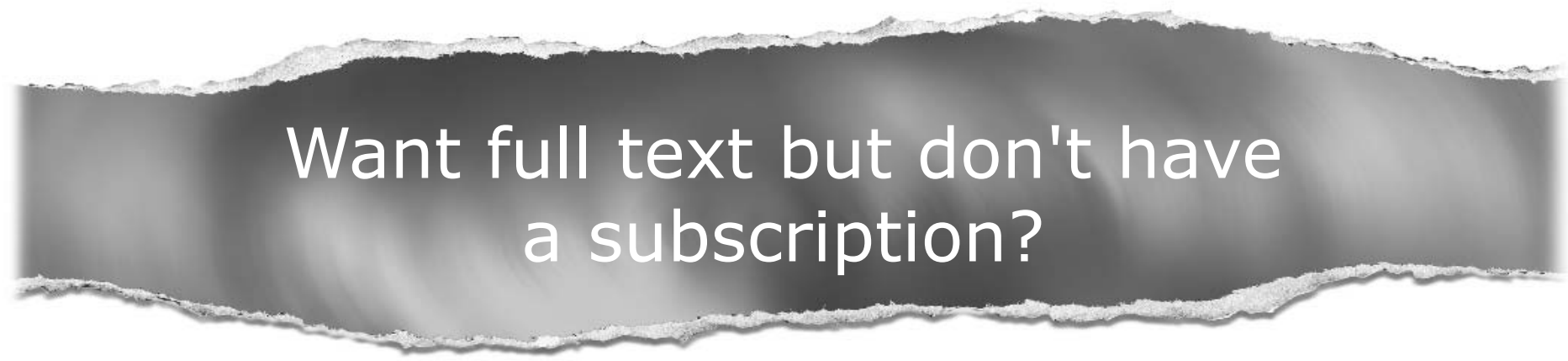

\section{Pay per view}

For just $\$ 8$ you can purchase the full text of individual articles using our secure online ordering service. You will have access to the full text of the relevant article for 48 hours during which time you may

download and print the pdf file for personal use.

\section{www.bjsportmed.com}

